\title{
Prevalence and predictors of premenstrual syndrome and premenstrual dysphoric disorder in a population-based sample
}

\author{
Sibil Tschudin • Paola Coda Bertea • Elisabeth Zemp
}

Received: 4 December 2009 /Accepted: 25 March 2010/Published online: 7 May 2010

(C) Springer-Verlag 2010

\begin{abstract}
The study aimed at assessing the prevalence of premenstrual symptoms and of premenstrual syndrome (PMS) and premenstrual dysphoric disorder (PMDD) in a population-based sample of women of the entire reproductive age range, as well as to analyse predictors of PMS and PMDD in terms of socio-demographic, health status and health behavioural factors. A set of questions on PMSbased on the premenstrual syndrome screening tool developed by Steiner et al., translated into German and piloted-was integrated into the written questionnaire of the 2007 Swiss Health Survey. Weighted prevalence rates and multivariable regression analysis for the outcome variables PMS and PMDD were calculated. A total of 3,913 women aged 15 to 54 years answered the questions on PMS symptoms, and 3,522 of them additionally answered the questions on interference of PMS with life. Ninety one percent of the participants reported at least one symptom, 10.3\% had PMS and 3.1\% fulfilled the criteria for PMDD. The prevalence of PMS was higher in nonmarried women, in women aged 35-44 years and in women of the Italian-speaking region of Switzerland. Both PMS and PMDD were strongly associated with poor physical
\end{abstract}

\section{S. Tschudin}

Department of Obstetrics and Gynaecology, University Hospital, Basel, Switzerland

P. C. Bertea $\cdot$ E. Zemp

Institute for Social and Preventive Medicine at the Swiss Tropical Institute, Associated Institute of the University of Basel,

Basel, Switzerland

S. Tschudin $(\bowtie)$

Division of Social Medicine and Psychosomatics,

Department of Obstetrics and Gynecology, University Hospital,

Spitalstrasse 21,

CH-4031 Basel, Switzerland

e-mail: stschudin@uhbs.ch health and psychological distress. Socio-cultural factors seem to determine the prevalence, perception and handling of PMS. Considering the association with poor physical health and high psychological distress, a broader underlying vulnerability in women qualifying for PMDD must be assumed and should be taken into account in clinical management as well as in future research in this field.

Keywords Premenstrual syndrome $\cdot$ PMS .

Premenstrual dysphoric disorder PMDD .

Prevalence $\cdot$ Predictors

\section{Introduction}

Premenstrual symptoms are common in women of reproductive age. It is estimated that up to $30 \%$ of women feel considerably bothered by premenstrually experienced symptoms, and that for 3-8\%, impairment due to dysphoric symptoms is so severe that they qualify for premenstrual dysphoric disorder (PMDD) as classified in DSM-IV (Woods et al. 1982; Johnson 1987; Rivera-Tovar and Frank 1990; Ramcharan et al. 1992; Merikangas et al. 1993; Sveindottir and Backstrom 2000; Angst et al. 2001; Wittchen et al. 2002; Halbreich et al. 2003). While PMDD is well defined, the criteria for the less pronounced manifestations of premenstrual syndrome (PMS) are less distinct. As a consequence, prevalence rates for PMDD have been quite consistent in epidemiological studies and surveys, whereas rates for PMS vary considerably depending on study design and instruments used (Woods et al. 1982; Johnson et al. 1988; Rivera-Tovar and Frank 1990; Ramcharan et al. 1992; Gehlert and Hartlage 1997; Hylan et al. 1999; Sveindottir and Backstrom 2000; Chawla et al. 2002; Cohen et al. 2002; Wittchen et al. 2002). Also, most 
information stems from community-based samples in the United States of America, while only a very limited number of studies have been conducted in Europe and Asia. Wittchen et al.'s study on a German community-based sample was limited to young women aged 14 to 24 years, and Angst et al.'s Zurich cohort study did not focus specifically on PMS, but assessed perimenstrual symptoms in a relatively small sample of 299 women aged 28 to 35 years (Angst et al. 2001; Wittchen et al. 2002). Therefore, population-based information for European countries still has to be confirmed.

Despite the considerable prevalence and impact of PMS, which make it even a popular topic in the media (especially in the USA), the World Health Report on mental health of 2001, listing as many as 2,000 disability rates for about 90 disorders, did not even mention PMS/PMDD (World Health Organisation 2001). This may reflect the fact that many professionals are still unaware of the impact of PMS on individuals, their families and environment (Halbreich et al. 2003). The few reports including work or family impairment show that PMS and PMDD most importantly influence marital relationships, housework and alsoalthough to a lower degree-work productivity and work absenteeism (Kuczmierczyk et al. 1992; Hylan et al. 1999; Chawla et al. 2002). Assessing PMS and PMDD in population-based health surveys not only provides the opportunity to determine the prevalence rates of PMS and PMDD, but also to assess their associations with socioeconomic and health factors, yielding a better understanding of such determinants and thus contributing to a better awareness, detection and treatment of these conditions.

So far, an association between PMS/PMDD and health factors such as smoking status and higher BMI could be identified, and according to Wittchen et al., women with PMDD had a high use of general and mental health services (Cohen et al. 2002; Wittchen et al. 2002; Masho et al. 2005; Potter et al. 2009). Concerning associations of PMS/PMDD with socio-demographic factors such as age, education and employment status, as well as with oral contraceptive (OC) use, the results of previous research are limited or not consistent (Cohen et al. 2002; Kurshan and Neill Epperson 2006; Takeda et al. 2006; Potter et al. 2009)

A prospective daily charting of symptoms, the clinical "gold standard" of the diagnosis of PMS/PMDD cannot be obtained in a health survey. However, the "Premenstrual Symptoms Screening Tool" (PSST), a screening instrument for severe PMS/PMDD developed by Steiner et al., offers a valuable alternative to such prospective assessments. It is based on DSM-IV criteria, tested in more than 500 women and yielded prevalence rates of PMS/PMDD that are comparable with those of several large studies assessing PMS/PMDD with prospective daily charting of symptoms (Steiner et al. 2003).
Based on these considerations, we aimed to assess the prevalence of premenstrual symptoms and of PMS and PMDD in a population-based sample of women spanning the entire reproductive age range. Furthermore, we wanted to analyse predictors of PMS and PMDD in terms of sociodemographic, health status and health behavioural factors.

\section{Methods}

Data and study population

The 2007 Swiss Health Survey was the fourth nationwide survey conducted every 5 years by the Swiss Federal Office of Statistics. The survey assessed detailed information on health status, health care utilisation and health-related behaviour. Data were collected from a random sample of persons aged 15 years and older living in Switzerland and speaking at least one of three interview languages (German, French or Italian). Subjects were asked to participate in a telephone interview and subsequently to fill in a written questionnaire. The participation rate of the telephone interview in 2007 was $66 \%(8,424$ men and 10,336 women). Of these, $77 \%$ returned the written questionnaire (6,308 men and 8,085 women).

The questions on premenstrual syndrome used in this paper were part of the written questionnaire. Only women aged 15 to 54 years were asked the respective questions on PMS. The screening tool (PSST) developed and described in detail by Steiner et al. was previously translated into German and pre-tested in 80 women, of whom 11 were patients with physician-diagnosed PMS or PMDD and 69 were healthy women (Steiner et al. 2003). The instrument included ten items with different premenstrual symptoms, each of which had to be rated with respect to the presence and intensity previous to and at the onset of the menstrual period. The symptom list was introduced with the question "Do you experience some or any of the following premenstrual symptoms which start before your period and stop within a few days of bleeding?" The list included the symptoms (1) anger/irritability, (2) anxiety/tension, (3) tearfulness/increased sensitivity to rejection, (4) depressed $\mathrm{mood} /$ hopelessness, (5) difficulty concentrating, (6) fatigue/ lack of energy, (7) overeating/food cravings, (8) insomnia or hypersomnia, (9) feeling overwhelmed or out of control and (10) physical symptoms such as breast tenderness, headaches, joint/muscle pain, bloating and weight gain. The tool furthermore asked whether such premenstrual symptoms interfered not at all, mildly, moderately or severely with (a) work efficiency, (b) relationships with co-workers or family, (c) social life activities and (d) home responsibilities. Due to restrictions with regard to the number of items that could be included in the Health Survey 
instrument, some of the PMS questions were dropped (decreased interest) or merged into one question (insomnia and hypersomnia, as well as the questions on interference of symptoms with relationships with co-workers and with family).

For diagnosing moderate to severe PMS and PMDD, the instructions of the premenstrual symptoms screening tool of Steiner et al. were followed: For PMDD/moderate to severe PMS, at least one of the symptoms (1) to (4) had to be severe/moderate to severe, at least four of the symptoms (1) to (10) had to be moderate to severe and one of the interferences (a), (b), (c) and (d) had to be severe/moderate to severe (Steiner et al. 2003).

\section{Statistical analyses}

Prevalence rates were calculated for each of the single premenstrual symptoms, for their interference with life, as well as for "moderate to severe PMS" and PMDD. Prevalence rates were weighted for the Swiss population, taking into account the particularities of the sampling strategy with regard to age, sex, nationality and living region (oversampling of some population segments had been done, such as for the Italian language region, in order to have sufficient sample sizes for region-specific health reporting; Calmonte et al. 2005).

Multivariable logistic regression analyses were conducted for the outcomes PMS and PMDD separately. We first performed regression analyses separately with groups of socio-demographic variables, health behaviour factors, health status indicators and oral contraception. We then performed the multivariable regressions, including in an overall model all those variables, which were significant in the sub-models at a $p$ level of $<0.05$. The model including oral contraceptives was calculated separately since only women up to age 49 had to answer the questions on contraception.

As socio-demographic variables, we included age (10 years groups from 15 to 54 years), marital status (married, unmarried, widowed and separated/divorced), nationality (Swiss, Italian, as the largest group of nonSwiss, and "others", including French, Spanish, Portuguese, former Yugoslavian and Turkish nationalities), language regions (German, French and Italian), education (university degree, college, secondary school, compulsory school, i.e., 8 years of education) and employment (full time, part time, no employment).

Health behaviour consisted of BMI (low $<18.5$, normal $18.5<25$, high $\geq 25<30$, very high $\geq 30$ ), physical activity (a score composed of different variables assessing the frequency and intensity of weekly physical activity and grading the activity as active, partially active, inactive), alcohol consumption (intake of pure alcohol per day and person, no consumption at all to less than once a month; mild consumption, up to $20 \mathrm{~g} \mathrm{day}^{-1}$; moderate to severe consumption, $\geq 20 \mathrm{~g} \mathrm{day}^{-1}$ ), smoking status (never smoker, ex-smoker, current smoker), psychotropic drug consumption within the last 7 days (no consumption, analgesics, antidepressants only, benzodiazepine only, antidepressants and benzodiazepine).

The group of health indicators included psychological distress and physical symptoms. Psychological distress was assessed by the Mental Health Inventory/Index, a component of MOS SF-36 that consists of a grading as none, moderate and severe of the five following items within the last 4 weeks: "have been a very nervous person", "have felt so down in the dumps that nothing could cheer up", "had felt calm and peaceful", "had felt downhearted and blue" and "had been a happy person" (Ware and Gandek 1998). Physical symptoms were assessed by a score based on the presence of backache, abdominal pain, headache, weakness, diarrhoea/constipation, sleep disturbance, palpitations and chest pain within the last 4 weeks and was graded as none, moderate or severe (Weiss et al. 1990). The statistical analysis was conducted using STATA/SE 8.0. Statistical significance was considered at $p<0.05$.

\section{Results}

A total of 3,913 women aged 15 to 54 years completed the questions on PMS symptoms, 3,522 of them also answered the questions on the interference of PMS with life. The weighted prevalence rates of the single premenstrual symptoms by degree of severity are shown in Table 1 . Fifty seven percent of the women reported having at least a mild degree of "anger/irritability" or "tearfulness/mood swings", two of the four core symptoms of PMDD, and about the same proportion reported "fatigue/lack of energy". Almost three quarters indicated having physical symptoms, such as breast tenderness, headaches, joint/ muscle pain, bloating and weight gain. Overall, $91 \%$ had at least one symptom of any degree of severity. The median duration of symptoms was 3 days, $90 \%$ indicated a time range of 5 days or less. Women felt most bothered in their relationship with co-workers and/or family (Table 2) and $6.4 \%$ reported severe interference of at least one symptom.

In Table 3, the weighted prevalence rates of PMS and PMDD are displayed by degree of severity and by several socio-demographic, health behaviour and health status factors, as well as by use of oral contraception $(n=3,522)$. From those women who provided information on both symptom severity as well as interference, 362 (14.46 unweighted and $10.30 \%$ weighted prevalence) had moderate to severe PMS and 111 (3.15\% unweighted and 3.10\% weighted) fulfilled the criteria for PMDD. 
Table 1 Weighted prevalence rates of premenstrual symptoms by degree of severity $(n=3,913)$

\begin{tabular}{|c|c|c|c|c|}
\hline & Not at all $(\%)$ & Mild (\%) & Moderate $(\%)$ & Severe $(\%)$ \\
\hline Anger or irritability & 43.0 & 30.4 & 18.8 & 7.8 \\
\hline Anxiety or tension & 72.7 & 15.5 & 9.3 & 2.5 \\
\hline Tearfulness or mood swings & 42.9 & 29.3 & 18.3 & 9.4 \\
\hline Depressed mood & 69.2 & 17.0 & 10.1 & 3.7 \\
\hline Difficulty concentrating & 82.1 & 11.9 & 4.5 & 1.5 \\
\hline Fatigue or lack of energy & 42.1 & 33.6 & 16.2 & 8.1 \\
\hline Overeating or food cravings & 58.6 & 19.8 & 12.8 & 8.8 \\
\hline Insomnia or hypersomnia & 71.7 & 14.9 & 9.2 & 4.2 \\
\hline Feeling overwhelmed or out of control & 88.3 & 7.2 & 3.1 & 1.5 \\
\hline $\begin{array}{l}\text { Physical symptoms: breast tenderness, headaches, } \\
\text { joint/muscle pain, bloating, weight gain }\end{array}$ & 26.1 & 27.2 & 26.9 & 19.8 \\
\hline
\end{tabular}

The results from the multivariable regression analyses are shown in Table 4. With regard to socio-demographic characteristics, PMS was associated with age (OR 1.64, 95\% CI 1.07-2.52 for women aged 35-44 years), marital status (OR 1.44, 95\% CI 1.05-1.96 for non-married women) and living region (OR 1.54, 95\% CI 1.01-2.34 for women of the Italian-speaking region). While in the sub-models elevated ORs were also seen for women of the French speaking region and for unemployed women, these associations were no longer significant in the overall model, pointing to confounding. No associations were seen between socio-demographic variables and PMDD.

Health indicators were significantly associated with PMS and with PMDD. The increase of the odds ratios was more pronounced for severe physical symptoms and psychological distress than for those of moderate degree. The association between moderate physical symptoms and PMDD was not significant, probably due to a too low number of affected women.

Among the health behaviour variables, PMS was associated with former smoking (OR 1.67, 95\% CI 1.22 2.27) and with self-reported use of psychotropic drugs, namely intake of analgesics (OR 1.44, 95\% CI 1.08-1.93) and benzodiazepines (OR 2.5, 95\% CI 1.44-4.34). PMS was less likely in women using oral contraceptives (OR $0.61,95 \%$ CI $0.40-0.93$ ). Significant associations were seen in the sub-models also for antidepressants and for the combinations of antidepressants and benzodiazepines, but disappeared in the overall model, pointing again to confounding. None of the health behaviour predictors were associated with PMDD.

\section{Discussion}

In this population-based sample of 3,913 women of the whole reproductive age in Switzerland, 91\% reported at least one premenstrual symptom. Of all participants $10.3 \%$ had PMS according to the DSM-IV criteria-based definition of Steiner and 3.1\% fulfilled the criteria for PMDD. The prevalence of PMS was higher in non-married women, in women aged 35-44 years and in women of the Italianspeaking region. It was furthermore associated with psychotropic drug use and was less likely in women using oral contraception. Both PMS and PMDD were strongly associated with poor physical health and psychological distress.

\section{Prevalence}

The $91 \%$ prevalence of any PMS symptom is in line with the results of previous studies, which have identified symptom prevalence rates of $75-95 \%$ (Johnson et al. 1988; Wilson and Keye 1989; Hylan et al. 1999; Wittchen et al. 2002; Perkonigg et al. 2004; Takeda et al. 2006; Vichnin et al. 2006; Campagne and Campagne 2007). The
Table 2 Weighted prevalence rates of interference of premenstrual symptoms with work, relationships, social life and home responsibilities $(n=3,522)$

\begin{tabular}{lcccc}
\hline & Not at all (\%) & Mild (\%) & Moderate (\%) & Severe (\%) \\
\hline Work efficiency & 56.5 & 31.3 & 9.5 & 2.7 \\
Relationships with co-workers or family & 48.5 & 35.9 & 11.7 & 3.8 \\
Social life activities & 63.3 & 27.3 & 7.5 & 1.9 \\
Home responsibilities & 60.3 & 28.9 & 8.0 & 2.9 \\
\hline
\end{tabular}


Table 3 Weighted prevalence rate of PMS/PMDD by degree of severity and by socio-demographic factors, health status and health behaviour $(n=3,522)$

\begin{tabular}{|c|c|c|c|c|}
\hline & Total $n(\%)$ & No/mild PMS $(\%)^{\mathrm{a}}$ & Moderate to severe PMS $(\%)^{\mathrm{a}}$ & $\operatorname{PMDD}(\%)^{\mathrm{a}}$ \\
\hline Overall & & 86.6 & 10.3 & 3.1 \\
\hline \multicolumn{5}{|l|}{ Socio-demographic factors } \\
\hline \multicolumn{5}{|l|}{ Age (years) } \\
\hline $15-24$ & $562(16.0)$ & 86.3 & 10.7 & 3.0 \\
\hline $25-34$ & $909(25.8)$ & 89.2 & 8.6 & 2.2 \\
\hline $35-44$ & $1,376(39.1)$ & 85.3 & 11.2 & 3.5 \\
\hline $45-54$ & $675(19.1)$ & 85.5 & 10.8 & 3.7 \\
\hline \multicolumn{5}{|l|}{ Marital status } \\
\hline Married & $1,705(48.5)$ & 87.1 & 9.6 & 3.3 \\
\hline Unmarried & $1,427(40.5)$ & 86.3 & 11.0 & 2.7 \\
\hline Widowed & $35(1.0)$ & 78.6 & 8.9 & 12.5 \\
\hline Separated/divorced & $353(10.0)$ & 85.3 & 11.3 & 3.4 \\
\hline \multicolumn{5}{|l|}{ Nationality } \\
\hline Swiss & $3,059(86.8)$ & 87.7 & 9.4 & 2.9 \\
\hline Italian & $73(2.1)$ & 83.8 & 8.4 & 7.8 \\
\hline Other & $390(11.1)$ & 83.3 & 13.7 & 3.0 \\
\hline \multicolumn{5}{|l|}{ Speaking regions } \\
\hline German & $2,131(60.5)$ & 88.2 & 9.4 & 2.4 \\
\hline French & $1,133(32.2)$ & 83.3 & 12.3 & 4.4 \\
\hline Italian & $258(7.3)$ & 81.0 & 13.1 & 5.9 \\
\hline \multicolumn{5}{|l|}{ Education } \\
\hline University degree & $995(28.3)$ & 87.3 & 10.5 & 2.2 \\
\hline College & $220(6.2)$ & 85.9 & 11.7 & 2.4 \\
\hline Secondary school & $2,953(58.3)$ & 86.8 & 9.8 & 3.4 \\
\hline Compulsory school & $254(7.2)$ & 83.9 & 11.9 & 4.2 \\
\hline \multicolumn{5}{|l|}{ Employment } \\
\hline Full time & $1,047(30.7)$ & 88.1 & 10.2 & 1.7 \\
\hline Part time & $1,607(47.1)$ & 87.7 & 9.1 & 3.2 \\
\hline No employment & $760(22.2)$ & 82.3 & 13.0 & 4.7 \\
\hline \multicolumn{5}{|l|}{ Health behaviour factors } \\
\hline \multicolumn{5}{|l|}{ BMI } \\
\hline Normal $(\geq 18.5<25)$ & $2,544(72.8)$ & 86.9 & 10.5 & 2.6 \\
\hline Low $(<18.5)$ & $253(7.2)$ & 86.7 & 6.5 & 6.8 \\
\hline High $(\geq 25<30)$ & $502(14.4)$ & 87.4 & 9.3 & 3.3 \\
\hline Very high $(\geq 30)$ & $195(5.6)$ & 82.2 & 13.8 & 4.0 \\
\hline \multicolumn{5}{|l|}{ Physical activity } \\
\hline Active & $1,391(39.5)$ & 87.6 & 10.1 & 2.3 \\
\hline Partially active & $1,728(49.1)$ & 86.8 & 10.0 & 3.2 \\
\hline Inactive & $402(11.4)$ & 82.6 & 11.9 & 5.5 \\
\hline \multicolumn{5}{|l|}{ Alcohol consumption } \\
\hline No consumption & $1,081(30.7)$ & 85.5 & 10.6 & 3.9 \\
\hline Mild consumption & $2,300(65.4)$ & 87.0 & 10.4 & 2.6 \\
\hline Moderate to severe consumption & $137(3.9)$ & 89.4 & 6 & 4.6 \\
\hline \multicolumn{5}{|l|}{ Smoking status } \\
\hline No smoker & $1,904(54.1)$ & 88.1 & 9.4 & 2.5 \\
\hline Ex-smoker & $602(17.1)$ & 82.3 & 13.1 & 4.6 \\
\hline Current smoker & $1,016(28.8)$ & 85.9 & 10.7 & 3.4 \\
\hline
\end{tabular}


Table 3 (continued)

\begin{tabular}{|c|c|c|c|c|}
\hline & Total $n(\%)$ & No/mild PMS (\%) ${ }^{\mathrm{a}}$ & Moderate to severe PMS $(\%)^{\mathrm{a}}$ & $\operatorname{PMDD}(\%)^{\mathrm{a}}$ \\
\hline \multicolumn{5}{|l|}{ Psychotropic drug consumption } \\
\hline No consumption & $2,570(73.0)$ & 88.3 & 9.1 & 2.6 \\
\hline Analgesics & $718(20.4)$ & 86.1 & 11.0 & 2.9 \\
\hline Antidepressants only & $77(2.2)$ & 76.4 & 16.3 & 7.3 \\
\hline Benzodiazepines only & $103(2.9)$ & 65.8 & 31.8 & 2.4 \\
\hline Antidepressants and benzodiazepines & $53(1.5)$ & 57.2 & 15.6 & 27.2 \\
\hline \multicolumn{5}{|l|}{ Health status factors } \\
\hline \multicolumn{5}{|l|}{ Psychological distress } \\
\hline None & $2,783(79.5)$ & 90.0 & 8.3 & 1.7 \\
\hline Moderate & $547(15.6)$ & 78.3 & 15.9 & 5.8 \\
\hline Severe & $173(4.9)$ & 63.8 & 19.4 & 16.8 \\
\hline \multicolumn{5}{|l|}{ Physical symptoms } \\
\hline None & $954(29.7)$ & 92.9 & 5.7 & 1.4 \\
\hline Moderate & $1,271(39.5)$ & 87.2 & 10.8 & 2.0 \\
\hline Severe & $990(30.8)$ & 81.8 & 13.3 & 4.9 \\
\hline \multicolumn{5}{|l|}{ Oral contraception } \\
\hline No & $1,446(71.1)$ & 84.3 & 11.3 & 4.4 \\
\hline Yes & $589(28.9)$ & 89.4 & 8.4 & 2.2 \\
\hline
\end{tabular}

${ }^{\mathrm{a}}$ As prevalence rates are weighted no indication of numbers

most common complaints in our study were physical symptoms, which were reported by $74 \%$ of women, followed by "fatigue/lack of energy" in $68 \%$ and "tearfulness/ mood swings" and "anger/irritability" in 67\% each. These findings are also approximately concordant with previous findings. In the prospective-longitudinal survey of Wittchen et al., the five most frequently reported symptoms were physical complaints (44.9\%), affect lability (41.7\%), fatigability (36.6\%), depressed mood (31.4\%) and appetite/craving (30.3\%). In Takeda et al.'s study, physical symptoms were reported by $81.2 \%$, "anger and irritability" by $70.6 \%$ and "anxiety and tension" by $68.5 \%$. The most prevalent psychological symptom in the Zurich cohort study was irritability (49.3\%).

The prevalence of moderate to severe PMS in our study was $14.5 \%$ (unweighted) and 10.3\% (weighted), respectively, pointing to the association of PMS with sociodemographic factors that were part of the sampling strategy. This prevalence rate is lower than the rate of $20.7 \%$ detected by Steiner et al. using the PSST, the screening instrument, on which our set of questions was based (Steiner et al. 2003). Steiner et al.'s sample, however, was from a primary care facility and was not community-based. Furthermore, the lower number of symptom items included in our questionnaire may have led to a slight underestimation of the prevalence. The rate in our study lies in between the prevalence of $5.3 \%$ detected by Takeda et al. in a Japanese sample and $31 \%$ found by Vichnin et al. in a U.S.American sample of adolescents and is close to the rate of
$13.6 \%$ found by Angst et al. in the Zurich cohort study (Angst et al. 2001; Takeda et al. 2006; Vichnin et al. 2006). In previous studies assessing the PMDD by means of DSMIV criteria, the range of prevalence rates was $1-8 \%(6.4 \%$ in The Harvard Study of Moods and Cycles by Cohen et al. including 4,164 older premenopausal women, 5.8\% over 12 months and 7.4\% over lifetime in Wittchen et al.'s prospective-longitudinal community-based study, $5.1 \%$ in Steiner et al.'s Canadian survey on a sample attending a primary care facility and $1.2 \%$ in the Japanese sample examined by Takeda et al.). A recently published prospective study on a randomly selected group of urban and rural women in the USA found a prevalence as low as Takeda et al.'s, when strictly claiming that all four diagnostic criteria had to be considered (Gehlert et al. 2009). In the Zurich cohort study, the prevalence of "severe PMS" was $8.1 \%$, but since diagnostic criteria were not consistent with DSM$\mathrm{IV}$, comparison is problematic. A prevalence of PMDD of $3.1 \%$ in the Swiss female population is on the lower side of the observed range. There were, however, significant differences between the three speaking regions with regard to the prevalence of PMDD as well as PMS: the prevalence was highest in the Italian, lower in the French and lowest in the German-speaking region. Cultural influences on perception of PMS related to socio-cultural background have been discussed in the literature, pointing to differences in vulnerability of various ethnic groups and to a diversity of illness beliefs (van den Akker et al. 1995). Furthermore, a traditional gender role orientation was found to be 
Table 4 Socio-demographic, health behaviour and health status factors associated with PMS and PMDD (multivariable regression analyses with groups of predictors and overall model)

\begin{tabular}{|c|c|c|c|c|}
\hline & \multicolumn{2}{|c|}{ Models including only groups of predictors } & \multicolumn{2}{|l|}{ Overall model } \\
\hline & \multicolumn{2}{|l|}{ OR $(95 \% \mathrm{CI})$} & \multicolumn{2}{|l|}{ OR $(95 \% \mathrm{CI})$} \\
\hline & PMS & PMDD & PMS $(n=3,002)$ & $\operatorname{PMDD}(n=3,094)$ \\
\hline \multicolumn{5}{|l|}{ Age (years) } \\
\hline $15-24$ & 1 & 1 & 1 & 1 \\
\hline $25-34$ & $1.21(0.81-1.82)$ & $0.96(0.46-2.02)$ & $1.20(0.79-1.84)$ & $0.76(0.34-1.67)$ \\
\hline $35-44$ & $1.57 *(1.04-2.37)$ & $1.24(0.60-2.58)$ & $1.64 *(1.07-2.52)$ & $1.18(0.54-2.56)$ \\
\hline $45-54$ & $1.36(0.85-2.16)$ & $1.09(0.48-2.46)$ & $1.28(0.78-2.09)$ & $0.79(0.32-1.95)$ \\
\hline \multicolumn{5}{|l|}{ Marital status } \\
\hline Married & 1 & 1 & 1 & 1 \\
\hline Unmarried & $1.48 *(1.09-2.01)$ & $1.20(0.68-2.12)$ & $1.44 *(1.05-1.96)$ & $0.98(0.55-1.75)$ \\
\hline Widowed & $0.39(0.05-2.93)$ & $1.28(0.17-9.8)$ & $0.35(0.05-2.67)$ & $1.39(0.17-11.19)$ \\
\hline Separated/divorced & $1.03(0.67-1.58)$ & $1.16(0.57-2.37)$ & $0.90(0.57-1.41)$ & $0.81(0.38-1.71)$ \\
\hline \multicolumn{5}{|l|}{ Nationality } \\
\hline Swiss & 1 & 1 & & \\
\hline Italian & $0.86(0.38-1.92)$ & $1.39(0.48-4.02)$ & & \\
\hline Other & $1.36(0.97-1.90)$ & $0.82(0.42-1.62)$ & & \\
\hline \multicolumn{5}{|l|}{ Speaking regions } \\
\hline German & 1 & 1 & 1 & 1 \\
\hline French & $1.28 *(1.01-1.63)$ & $1.58 *(1.05-2.39)$ & $1.11(0.85-1.44)$ & $1.30(0.82-2.07)$ \\
\hline Italian & $1.69 * *(1.14-2.50)$ & $2.07 *(1.09-3.92)$ & $1.54 *(1.01-2.34)$ & $1.59(0.77-3.32)$ \\
\hline \multicolumn{5}{|l|}{ Education } \\
\hline Compulsory school & 1 & 1 & & \\
\hline Secondary school & $1.20(0.73-1.95)$ & $0.74(0.27-2.02)$ & & \\
\hline College & $1.08(0.83-1.41)$ & $1.23(0.76-1.98)$ & & \\
\hline University degree & $0.74(0.43-1.25)$ & $1.43(0.67-3.09)$ & & \\
\hline \multicolumn{5}{|l|}{ Employment } \\
\hline Full time & 1 & 1 & 1 & 1 \\
\hline Part time & $1.13(0.85-1.50)$ & $1.81 *(1.05-3.12)$ & $1.02(0.75-1.38)$ & $1.62(0.90-2.91)$ \\
\hline No Employment & $1.56^{* *}(1.12-2.18)$ & $2.28 * *(1.25-4.18)$ & $1.30(0.92-1.85)$ & $1.44(0.75-2.76)$ \\
\hline \multicolumn{5}{|l|}{ Oral contraception $^{\mathrm{a}}$} \\
\hline No & 1 & 1 & 1 & 1 \\
\hline Yes & $0.79(0.57-1.10)$ & $0.59(0.32-1.10)$ & $0.61 *(0.40-0.93)^{\mathrm{a}}$ & $0.52(0.25-1.08)^{\mathrm{a}}$ \\
\hline \multicolumn{5}{|l|}{ Psychological distress } \\
\hline None & 1 & 1 & 1 & 1 \\
\hline Moderate & $1.43 *(1.06-1.94)$ & $2.35 * * *(1.40-3.96)$ & $1.44 *(1.05-1.97)$ & $2.41 * * *(1.42-4.09)$ \\
\hline Severe & $2.43 * * *(1.54-3.83)$ & $6.62 * * *(3.64-12.05)$ & $2.17 * *(1.32-3.56)$ & $6.65 * * *(3.41-12.97)$ \\
\hline \multicolumn{5}{|l|}{ Physical symptoms } \\
\hline None & 1 & 1 & 1 & 1 \\
\hline Moderate & $1.56^{* *}(1.14-2.15)$ & $1.89 * * *(0.94-3.80)$ & $1.55^{* *}(1.11-2.16)$ & $1.84(0.91-3.72)$ \\
\hline Severe & $2.03 * * *(1.45-2.84)$ & $2.51 * * *(1.23-5.09)$ & $1.79 * * *(1.25-2.57)$ & $2.28 *(1.10-4.72)$ \\
\hline \multicolumn{5}{|l|}{ BMI } \\
\hline Normal $(\geq 18.5<25)$ & 1 & 1 & & \\
\hline Low $(<18.5)$ & $0.63(0.38-1.03)$ & $1.49(0.77-2.88)$ & & \\
\hline High $(\geq 25<30)$ & $0.77(0.55-1.07)$ & $1.22(0.73-2.05)$ & & \\
\hline Very high $(\geq 30)$ & $0.92(0.57-1.49)$ & $0.83(0.35-1.98)$ & & \\
\hline
\end{tabular}


Table 4 (continued)

Models including only groups of predictors

OR $(95 \% \mathrm{CI})$

\section{PMS}

1

$1.12(0.88-1.43)$

$1.25(0.87-1.80)$

Inactive

Alcohol consumption

No consumption

Mild consumption

Moderate to severe consumption

Smoking status

No smoker

Ex-smoker

Current smoker

Psychotropic drug consumption

No consumption

Analgesics

Antidepressants only

Benzodiazepines only

Antidepressants and benzodiazepines

\section{1}

$0.80(0.63-1.02)$

$0.54(0.27-1.07)$

1

$1.46 *(1.10-1.96)$

$1.03(0.79-1.35)$

1

$1.45 * *(1.11-1.89)$

$1.93 *(1.00-3.75)$

$3.71 * * *(2.32-5.96)$

$3.04 * *(1.42-6.51)$
1

$0.96(0.63-1.48)$

$1.59(0.91-2.78)$

\section{1}

$0.66 *(0.44-1.00)$

$0.63(0.22-1.82)$

1

$0.81(0.62-1.05)$

$0.54(0.27-1.09)$

$0.89(0.56-1.41)$

$0.60(0.17-2.08)$

\section{1}

$1.43(0.84-2.41)$

$1.31(0.84-2.05)$

1

$1.67 * *(1.22-2.27)$

1

$1.03(0.77-1.38)$

$1.57(0.89-2.75)$

$1.14(0.69-1.89)$

1

$1.57(0.99-2.50)$

1

$1.44 *(1.08-1.93)$

1

$3.23 * *(1.34-7.80)$

$1.10(0.50-2.41)$

$1.20(0.71-2.03)$

$1.19(0.37-3.88)$

$2.50 * *(1.44-4.34)$

$1.72(0.63-4.73)$

$0.38(0.09-1.66)$

9.97*** (4.80-20.70)

$1.75(0.73-4.17)$

$1.62(0.57-4.60)$

$* p<0.05, * * p<0.01, * * * p<0.001$

${ }^{a}$ A separate model was calculated to analyse the association with oral contraceptives since only women up to age 49 had to answer the respective questions; these models included $n=1,731$ for PMS and $n=1,793$ for PMDD

associated with higher premenstrual distress (Anson 1999). We speculate that such factors may contribute to the higher rates in women living in one of the two Romance languages speaking regions.

\section{Predictors}

\section{Socio-demographic factors}

In previous research, associations between sociodemographic factors and PMS/PMDD are not consistent. In our study, PMS/PMDD was more prevalent in women of advanced reproductive age, in those with lower education and in those without employment. In Takeda et al.'s survey and Potter et al.'s cohort study on 2,863 French women, there was no association with advanced age, whereas in several other studies, age dependency could not be analysed due to a narrow age range of the samples (Takeda et al. 2006; Potter et al. 2009). Cohen et al. found an association with lower education, while Potter et al. did not. In Potter et al.'s study, there was no association with employment status, while Cohen et al.'s results with regard to employment contrasted with ours, as women not working outside the home were less likely to meet criteria for PMDD.
In a cross-sectional population-based Swedish survey focusing on associations between women's general health and employment status and work conditions, it was shown that unemployed women and those exposed to job strain had an increased odd ratio for a high level of common symptoms (Krantz and Ostergren 2000). These findings can be considered in line with our results and would support the theory of a negative correlation between level of control and perceived symptom severity.

\section{Hormonal contraceptives}

PMS was less likely in OC users in our study. Diverse results have been reported of several studies investigating the interaction of $\mathrm{OC}$ use and premenstrual syndrome. Some earlier results suggested no benefits with regard to mood symptoms or even a negative influence of OCs on PMS, such as prolonged negative mood, whereas more recent studies attributed a beneficial effect to OCs, especially on physical premenstrual symptoms and preparations with third generation progestogens and drospirenone showed even a positive effect on psychological symptoms (Graham and Sherwin 1992; Bancroft and Rennie 1993; Graham and Sherwin 1993; Oinonen and Mazmanian 2002; 
Kurshan and Neill Epperson 2006). Globally, OCs were found to have little impact on the pattern and incidence of menstrual symptoms (Ross et al. 2003). Whereas in a study comparing women with and without adverse mood effects from combined oral contraceptives (COCs), Segebladh et al. found a significantly increased prevalence of mood disorders and premenstrual syndrome in women with mood effects under COCs (Segebladh et al. 2009). The existing results suggest that the therapeutic effect of COCs, imitating the natural ovarian cycle, is minor and that an underlying vulnerability might have a stronger influence. The partially beneficial effect could be explained by the enhancement of patients' feeling of control through COCinduced cycle stability.

\section{Health behaviour}

Former but not current smoking was predictive for PMS. Current smoking revealed to be associated with a higher incidence of PMS in several former studies (Cohen et al. 2002; Wittchen et al. 2002). In Bertone-Johnson et al.'s casecontrol study, smokers were 2.1 times as likely to develop PMS as were never smokers, and women with onset of smoking during adolescence were at highest risk (BertoneJohnson et al. 2008). High BMI was shown to be associated with PMS in various studies as well; in our study, it wasalthough not significantly - higher in women with a BMI of 30 or more (Masho et al. 2005; Potter et al. 2009).

\section{Health status}

Physical and psychological health status factors had the strongest predictive power for PMS and especially for PMDD in our study. This is in line with Wittchen et al., who demonstrated a high use of general health and mental health services in women with PMDD (Wittchen et al. 2002).

\section{Divergences in PMS and PMDD predictors}

Predictors for PMS and PMDD were not identical in our study. Consumption of antidepressants, consumption of antidepressants and benzodiazepines, psychological distress and presence of severe physical symptoms were predominantly associated with PMDD. This might be due to more pronounced symptoms of women with PMDD, but favours also the theory that women with psychiatric comorbidity, namely depressive and anxiety disorders, are particularly prone to PMDD (De Ronchi et al. 2005).

\section{Strengths/limitations}

The size and representativity of our population-based sample is a strength of our study. With $66 \%$ of approached people participating in the telephone interview and $77 \%$ of those answering the questionnaire, the participation rate was within the expected limits. It is likely, however, that there was a higher prevalence of PMS or PMDD among non-responders. Assessments of physical and psychological health were based on self-report and were therefore entirely subjective. Another limitation of our study is the fact that the German-language PSST has only been piloted on a limited German-speaking sample and has not yet been thoroughly validated. With regard to marital status, the Swiss Health Survey did not further differentiate the category of unmarried women, thus no further distinction was possible between women with or without a partner. As the group of women of the category "unmarried" certainly also included some women with a partner, the odds ratio for "unmarried" in the sense of "single" women may in fact even be higher; thus our finding might be a conservative estimate. Only $3 \%$ of the large, population-based sample is qualified for PMDD. As a consequence, the analysis of determinants for PMDD was limited due to the small size of several sub-samples, e.g., the prevalence of PMDD in widows seemed high $(12.5 \%)$, but resulted, in fact, from just two cases.

\section{Conclusion}

Almost $15 \%$ of women of reproductive age in Switzerland had premenstrual symptoms to an extent requiring treatment; in 3\%, the criteria for PMDD were met. Sociocultural factors such as age and affiliation to a particular language region seem to determine the prevalence, perception and handling of PMS, pointing to differences in vulnerability of various ethnic groups. We could demonstrate that PMS is associated with consumption of psychoactive medications. Considering the association with poor physical health and high psychological distress, a broader underlying vulnerability in women qualifying for PMDD must be assumed and should be taken into account in clinical management as well as in future research in this field.

\section{References}

Angst J, Sellaro R et al (2001) The epidemiology of perimenstrual psychological symptoms. Acta Psychiatr Scand 104(2):110-116

Anson O (1999) Exploring the bio-psycho-social approach to premenstrual experiences. Soc Sci Med 49(1):67-80

Bancroft J, Rennie D (1993) The impact of oral contraceptives on the experience of perimenstrual mood, clumsiness, food craving and other symptoms. J Psychosom Res 37(2):195-202

Bertone-Johnson ER, Hankinson SE et al (2008) Cigarette smoking and the development of premenstrual syndrome. Am J Epidemiol 168(8):938-945 
Calmonte R, Galati-Petrecca M et al (2005) Gesundheit und Gesundheitsverhalten in der Schweiz 1992-2002. B. f. Statistik, Neuchâtel

Campagne DM, Campagne G (2007) The premenstrual syndrome revisited. Eur J Obstet Gynecol Reprod Biol 130(1):4-17

Chawla A, Swindle R et al (2002) Premenstrual dysphoric disorder: is there an economic burden of illness? Med Care 40(11):11011112

Cohen LS, Soares CN et al (2002) Prevalence and predictors of premenstrual dysphoric disorder (PMDD) in older premenopausal women. The Harvard Study of Moods and Cycles. J Affect Disord 70(2):125-132

De Ronchi D, Ujkaj M et al (2005) Symptoms of depression in late luteal phase dysphoric disorder: a variant of mood disorder? J Affect Disord 86(2-3):169-174

Gehlert S, Hartlage S (1997) A design for studying the DSM-IV research criteria of premenstrual dysphoric disorder. J Psychosom Obstet Gynaecol 18(1):36-44

Gehlert S, Song IH et al (2009) The prevalence of premenstrual dysphoric disorder in a randomly selected group of urban and rural women. Psychol Med 39(1):129-136

Graham CA, Sherwin BB (1992) A prospective treatment study of premenstrual symptoms using a triphasic oral contraceptive. J Psychosom Res 36(3):257-266

Graham CA, Sherwin BB (1993) The relationship between mood and sexuality in women using an oral contraceptive as a treatment for premenstrual symptoms. Psychoneuroendocrinology 18(4):273281

Halbreich U, Borenstein J et al (2003) The prevalence, impairment, impact, and burden of premenstrual dysphoric disorder (PMS/ PMDD). Psychoneuroendocrinology 28(Suppl 3):1-23

Hylan TR, Sundell K et al (1999) The impact of premenstrual symptomatology on functioning and treatment-seeking behavior: experience from the United States, United Kingdom, and France. J Womens Health Gend Based Med 8(8):1043-1052

Johnson TM (1987) Premenstrual syndrome as a western culturespecific disorder. Cult Med Psychiatry 11(3):337-356

Johnson SR, McChesney C et al (1988) Epidemiology of premenstrual symptoms in a nonclinical sample. I. Prevalence, natural history and help-seeking behavior. J Reprod Med 33(4):340-346

Krantz G, Ostergren PO (2000) Common symptoms in middle aged women: their relation to employment status, psychosocial work conditions and social support in a Swedish setting. J Epidemiol Community Health 54(3):192-199

Kuczmierczyk AR, Labrum AH et al (1992) Perception of family and work environments in women with premenstrual syndrome. J Psychosom Res 36(8):787-795

Kurshan N, Neill Epperson C (2006) Oral contraceptives and mood in women with and without premenstrual dysphoria: a theoretical model. Arch Womens Ment Health 9(1):1-14

Masho SW, Adera T et al (2005) Obesity as a risk factor for premenstrual syndrome. J Psychosom Obstet Gynaecol 26(1):33-39

Merikangas KR, Foeldenyi M et al (1993) The Zurich Study. XIX. Patterns of menstrual disturbances in the community: results of the Zurich Cohort Study. Eur Arch Psychiatry Clin Neurosci 243 (1):23-32
Oinonen KA, Mazmanian D (2002) To what extent do oral contraceptives influence mood and affect? J Affect Disord 70(3):229 240

Perkonigg A, Yonkers KA et al (2004) Risk factors for premenstrual dysphoric disorder in a community sample of young women: the role of traumatic events and posttraumatic stress disorder. J Clin Psychiatry 65(10):1314-1322

Potter J, Bouyer J et al (2009) Premenstrual syndrome prevalence and fluctuation over time: results from a French population-based survey. J Womens Health (Larchmt) 18(1):31-39

Ramcharan S, Love EJ et al (1992) The epidemiology of premenstrual symptoms in a population-based sample of 2650 urban women: attributable risk and risk factors. J Clin Epidemiol 45(4):377-392

Rivera-Tovar AD, Frank E (1990) Late luteal phase dysphoric disorder in young women. Am J Psychiatry 147(12):1634-1636

Ross C, Coleman G et al (2003) Prospectively reported symptom change across the menstrual cycle in users and non-users of oral contraceptives. J Psychosom Obstet Gynaecol 24(1):15-29

Segebladh B, Borgstrom A et al (2009) Prevalence of psychiatric disorders and premenstrual dysphoric symptoms in patients with experience of adverse mood during treatment with combined oral contraceptives. Contraception 79(1):50-55

Steiner M, Macdougall M et al (2003) The premenstrual symptoms screening tool (PSST) for clinicians. Arch Womens Ment Health 6(3):203-209

Sveindottir H, Backstrom T (2000) Prevalence of menstrual cycle symptom cyclicity and premenstrual dysphoric disorder in a random sample of women using and not using oral contraceptives. Acta Obstet Gynecol Scand 79(5):405-413

Takeda T, Tasaka K et al (2006) Prevalence of premenstrual syndrome and premenstrual dysphoric disorder in Japanese women. Arch Womens Ment Health 9(4):209-212

van den Akker OB, Eves FF et al (1995) Menstrual cycle symptom reporting in three British ethnic groups. Soc Sci Med 40 (10):1417-1423

Vichnin M, Freeman EW et al (2006) Premenstrual syndrome (PMS) in adolescents: severity and impairment. J Pediatr Adolesc Gynecol 19(6):397-402

Ware JE Jr, Gandek B (1998) Overview of the SF-36 Health Survey and the International Quality of Life Assessment (IQOLA) Project. J Clin Epidemiol 51(11):903-912

Weiss W, Spuhler T et al (1990) Enquête auprès de la population "La santé et la promotion de la santé". Rapport final. Etude intercantonale sur les indicatuers de santé (IGIP-PROMES). Lausanne, Institut Suisse de la Santé Publique et des Hôpitaux ISH/SKI

Wilson CA, Keye WR Jr (1989) A survey of adolescent dysmenorrhea and premenstrual symptom frequency. A model program for prevention, detection, and treatment. J Adolesc Health Care 10 (4):317-322

Wittchen HU, Becker E et al (2002) Prevalence, incidence and stability of premenstrual dysphoric disorder in the community. Psychol Med 32(1):119-132

Woods NF, Most A et al (1982) Prevalence of perimenstrual symptoms. Am J Public Health 72(11):1257-1264

World Health Organisation (2001) Mental health: new understanding, new hope. WHO, Geneva 